\title{
PENGARUH RELIGIUSITAS TERHADAP ETIKA KONSUMEN PADA GENERASI MILENIAL
}

\author{
Ali Wardhana \\ Fakultas Ilmu Sosial dan Humaniora, Universitas Bunda Mulia \\ email: awardhana@bundamulia.ac.id
}

\begin{abstract}
Ethics plays an important role in human life, including in the millennial generation. Ethical assessment in the millennial generation needs attention from producers, considering this generation is a potential market. Thus the purpose of this study is to see the effect of religiosity on consumer ethics in the millennial generation. This study will use primary data and the questionnaireinstrument. The results showed that intrinsic religiosity had a negative effect on ethical judgment while extrinsic religiosity had a positive influence on ethical judgment.
\end{abstract}

Keywords: religiosity, generation milenial, ethic judgement

\begin{abstract}
ABSTRAK
Etika memainkan peran penting dalam kehidupan manusia, termasuk pada generasi milenial. Penilain etika pada generasi milenial perlu mendapat perhatian oleh para produsen, mengingat generasi ini merupakan pasar yang potensial. Dengan demikian tujuan penelitian ini hendak melihat pengaruh religiusitas terhadap etika konsumen pada generasi milenial. Penelitian ini akan mengggunakan data primer dan intrumen penelitian berupa kuisoner. Hasil penelitian menunjukan bahwa intrinsic religiosity berpengaruh negatif pada penilaian etika sedangkan extrinsic religiosity memberi pengaruh positif pada penilaian etika.
\end{abstract}

Kata Kunci : religiusitas, generasi milenial, penilaian etika

\section{A. LATAR BELAKANG}

Etika memainkan peran dalam pengambilan keputusan pada generasi milenial. Sebagai contoh, laporan yang diterbitkan oleh Morning Consult pada tahun 2018 yang menunjukan bahwa hanya $25 \%$ dari generasi milenial yang mengatakan bahwa mereka membeli barang atau jasa dari perusahaan meskipun mereka sadar perusahaan memiliki praktik perburuhan yang tidak mereka dukung. Dengan kata lain, hanya $25 \%$ generasi milenial yang mengabaikan penilaian etika dalam pengambilan keputusan. Hal tersebut dapat memberikan gambaran tentang peranan penting etika bagi pada produsen barang dan jasa. Pada sisi lain, beberapa negara seperti Indonesia, generasi milenial merupakan pangsa pasar yang potensial. Generasi ini juga di prediksi akan akan mengalami puncak dar ifenomena bonus demografi pada tahun 2030 (bkkbn.go.id), oleh karena itu, perlu memahami bagaimana etika di generasi milenial Indonesia sebagai konsumen yang potensial. Selain itu etika ini juga menjadi sesuatu yang penting dalam pembangunan karakter bangsa yang lebih baik. Lantas 


\section{JURNAL EKONOMI DAN MANAJEMEN \\ P-ISSN: 2598-9022/ E-ISSN: 2598-9618 \\ Available at: \\ http://e-journal.unipma.ac.id/index.php/capital}

apakah yang mempengaruhi penilaian etika seorang individu?

Menurut penelitian Agag dan Elmasry (2015) dan penelitianArli (2017) faktor penting yang mempengaruhi penilaian etika adalah agama. Penelitian lain juga mengungkapkan bahwa nilai agama memainkan peran penting dalam mengembangkan dan mengasah persepsi, sikap dan perilaku individu termasuk penilaian etika (Madni et al, 2016).

Kamus besar bahasa Indonesia sendiri mendefinisikan agama sebagai ajaran, sistem yang mengatur tata keimanan (kepercayaan) dan peribadatan kepada Tuhan Yang Mahakuasa serta tata kaidah yang berhubungan dengan pergaulan manusia dan manusia serta manusia dan lingkungannya. Religiusitas sendiri merupakan salah satu nilai positif yang masih dipegang di generasi muda Indonesia selain saling membantu dan keramahan (Sihombing, 2014). Penelitian lain oleh Pew Research Center menemukan bahwa 93\% penduduk Indonesia percaya bahwa agama memegang peranan yang penting dalam kehidupan manusia. Angka tersebut jauh melampaui ratarata negara maju seperti amerika serikat.
Oleh karena itu tidaklah mengherankan bila ternyata agama memainkan peran penting pada generasi milenial di Indonesia.

Survey pada tahun 2017 dari Varkey Foundation yang melakukan survey pada 20.000 anak muda pada 20 negara di dunia. Hasilnya menunjukan bahwa 93\% anak muda Indonesia menganggap bahwa keyakinan agama atau komitmen terhadap keyakinan agama merupakan kunci dari kebahagian dimana angka tersebut jauh diatas rata-rata dunia sebesar $42 \%$. Pengaruh agama terhadap generasi milenial juga nampak pada kenaikan pilihan baju muslimah ala Timur Tengah dikalangan mahasiswa dan pelajar (Purwandi dan Ali, 2018). Lebih lanjut dalam riset terebut mengatakan bahwa generasi milenial akan cenderung mencari ketenangan melalui agama bila sudah mengalami kejenuhan dengan keduniawian. Berbagai survey tersebut dapat memberi gambaran bagaimana agama pada generasi milenial. Bagi generasi milenial agama bukan lagi mengenai kepercayaan, melainkan juga identitas diri dan dasar dalam penentukan sesuatu. 


\section{JURNAL EKONOMI DAN MANAJEMEN \\ P-ISSN: 2598-9022/ E-ISSN: 2598-9618 \\ Available at: \\ http://e-journal.unipma.ac.id/index.php/capital}

Berbeda dengan berbagai hasil survey yang dipaparkan, survey oleh CSIS tahun 2017 menunjukan fakta mengejutkan. Dalam survey tersebut generasi milenial lebih memilih kegiatan olahraga sebagai kegiatan yang paling menarik. Pada satu sisi generasi milenial agama penting dan menjadi sumber kebahagian, namun mereka tidak memilih kegiatan olahraga sebagai kegiatan yang menarik. Generasi milenial justru memilih kegiatan olahraga sebagai kegiatan yang menarik.

Merujuk pada hasil survey tersebut dimana terdapat ketidakkonsistenan dan peran penting etika sebagai salah satu penentu tindakan pada generasi yang memiliki akses yang begitu luas terhadap informasi sehingga diduga akan mempengaruhi penilaian etika maka mendorong penelitian ini, Penelitian ini juga merujuk pada saran penelitian yang bersumber pada penelitian Arli et al (2017) untuk melakukan perbandingan penilaian etika antara generasi milenial yang tinggal di perkotaan dan pedesaan, namun karena keterbatasan penelitian, maka penelitian ini hanya berfokus untuk melihat pengaruh religiusitas terhadap etika konsumen pada generasi milenial yang tinggal di perkotaan (Jabodetabek).

\section{B. TINJAUAN PUSTAKA}

Religiusitas merupakan sebuah konsep multidimensi dan kompleks yang digunakan untuk mengukur komitmen keagamaan dan ketaatan individu (Abdulrazak dan Gbadamosi, 2017). Agar religiusitas yang komplek dapat dijelaskan maka digunakan 2 kutub yang berbeda untuk menjelaskan tentang religiusitas, yaitu motivasi ekstrinsik dimana manusia menggunakan religiusitas tersebut, dan motivasi intrinsic dimana manusia menghidupi agama yang ia yakini (Allport dan Ross, 1967). Lebih lanjut, motivasi ekstrinsik akan melihat religiusitas sebagai instrumental, seperti penggunaan aksesoris yang menunjukan identitas agama tertentu, sedangkan motivasi intrinsik berbicara religiusitas sebagai motivasi utama dalam hidup.

Penilaian etika adalah derajat dimana perilaku dalam pertanyaan adalah disadari dapat diterima individu secara moral dan sangat bergantung pada pelajaran yang diajarkan dari pendidikan dini di rumah tentang keadilan, benar dan salah, sebagaimana 


\section{JURNAL EKONOMI DAN MANAJEMEN \\ P-ISSN: 2598-9022/ E-ISSN: 2598-9618 \\ Available at:}

http://e-journal.unipma.ac.id/index.php/capital

dikomunikasikan melalui pendidikan agama dan moral dari cerita dongeng (Swimberghe et al, 2011).

Penilaian etika diukur dengan menggunakan consumer ethics scale (CES) yang disusun oleh Muncy dan Vitell (1992) yang kemudian dimodifikasi dan terdapat penambahan item pada tahun 2005 (Vitell, 2005).Consumer ethics scale (CES) sendiri terdiri dari aktif mengambil manfaat dari kegiatan illegal, secara pasif mengambil manfaat, secara aktif mengambil manfaat dari praktik yang menipu (atau dipertanyakan) tetapi legal, tidak ada kegiatan kotor, mendownload materi yang memiliki hak cipta/ membeli barang palsu, daur ulang/ kesadaran lingkungan dan melakukan hal yang benar/ berbuat baik.

Religiusitas dan etika berhubungan erat karena religiusitas individu merupakan peran fundamental dalam perkembangan etika (Vitell, 2010). Sebagian besar penelitian terdahulu mengungkapkan bahwa religiusitas intrinsik memiliki efek negatif, sedangkan religiusitas ekstrinsik beberapa penelitian menujukan tidak terdapat efek dan beberapa penelitian menunjukan memiliki efek positif (Denni, 2017). Hubungan religiusitas dan etika juga tergambarkan dalam kerangka konseptual (Denni, 2017) sebagai berikut:

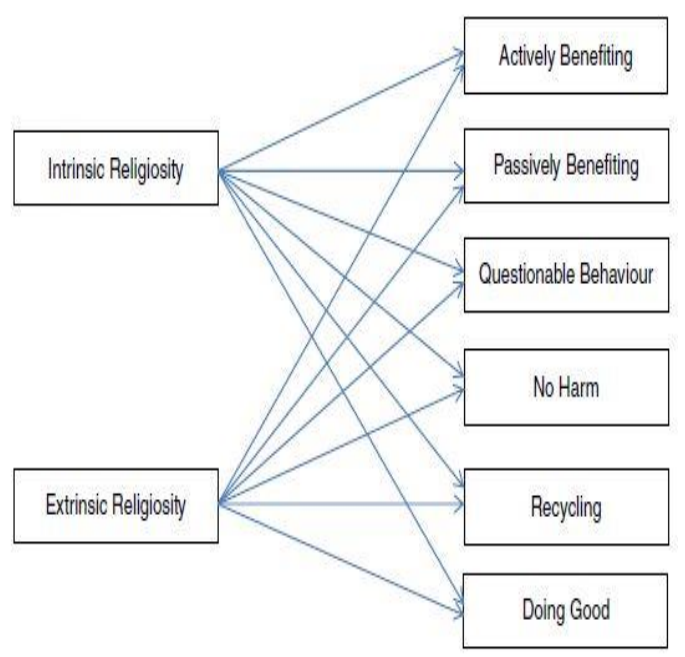

Gambar 1. Kerangka Konseptual

Merujuk pada kerangka konseptual tersebut maka terbentuk 2 hipotesis, yaitu :

H1 = Intrinsic religiosity akan memberi pengaruh terhadap penilaian etika yang meliputi: memberi manfaat secara aktif, memberi manfaat secara pasif, perilaku yang dapat dipertanyakan, tidak merusak dan mempengaruhi secara positif, mendaur ulang dan bertindak yang baik

$\mathrm{H} 2=$ Extrinsic religiosity akan memberi pengaruh terhadap penilaian etika yang meliputi memberi manfaat secara aktif, 


\section{JURNAL EKONOMI DAN MANAJEMEN \\ P-ISSN: 2598-9022/ E-ISSN: 2598-9618 \\ Available at: \\ http://e-journal.unipma.ac.id/index.php/capital}

memberi manfaat secara pasif, perilaku yang dapat dipertanyakan, tidak merusak dan mempengaruhi secara positif, mendaur ulang dan bertindak yang baik

\section{METODE PENELITIAN}

Penelitian ini menggunakan jenis dan sumber data primer dan instrument penelitian berupa kuisoner. Desain metodologi yang digunakan berupa cross sectional, mengingat informasi akan diperoleh dengan menggunakan sampel pada satu titik waktu tertentu (Leavy, 2017). Data diperoleh secara langsung dari responden berdasarkan hasil penyebaran kuesioner baik secara luring maupun melalui daring. Populasi pada penelitian ini adalah generasi milenial pada rentang usia 18-30 tahun (generasi milenial) yang berdomisili di Jabodetabek. Variabel-variabel yang diteliti adalah religiusitas yang menggunakan 2 variabel yaitu intrinsic religiosity dan extrinsic religiosity sebagai variabel independen serta keyakinan etika yang meliputi: memberi manfaat secara aktif, memberi manfaat secara pasif, perilaku yang dapat dipertanyakan, tidak merusak dan mempengaruhi secara positif, mendaur ulang dan bertindak yang baik sebagai variabel dependen.Variabel religiusitas diukur dengan merujuk pada penelitian Allport dan Ross (1967). Variabel penilaian etika akan di gunakan skala Muncy dan Vitell's CES.

Setiap variabel akan menggunakan skala rating yang umum digunakan yaitu skala Likert. Jenis skala ini didesain untuk menguji seberapa kuat responden setuju dengan sebuah pernyataan yang mengikuti pola 1 = sangat tidak setuju, 2 = tidak setuju, $3=$ netral, $4=$ setuju dan $5=$ sangat setuju (Sekaran dan Bougie, 2016). Pada kedua variabel independen masing-masing akan dikur dengan 5 indikator, yaitu intrinsic religiosity akan diukur dengan menggunakan I1, I2, I3, I4, I5, dan extrinsic religiosity akan diukur dengan menggunakan E1, E2, E3, E4, E5. Pada variabel dependen diukur dengan indikator yang berbeda. Memberi manfaat secara aktif akan diukur dengan menggunakan A1, A2, A3, A4, memberi manfaat secara pasif akan diukur dengan menggunakan P1, P2, P3, perilaku yang dapat dipertanyakan akan diukur dengan menggunakan Q1, Q2, Q3，Q4，Q5, tidak merusak dan mempengaruhi 


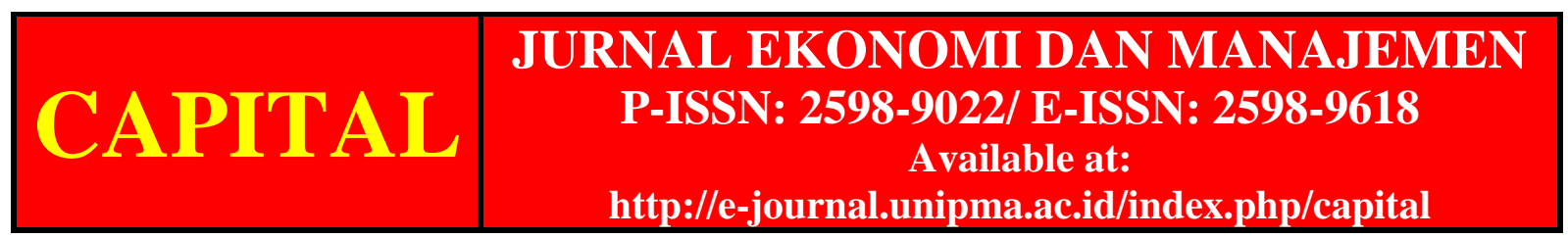

secara positif akan diukur dengan menggunakan N1, N2, N3, mendaur ulang akan diukur dengan menggunakan R1, R2, R3 dan bertindak yang baik akan diukur dengan D1, D2, D3, D4.

\section{HASIL DAN PEMBAHASAN}

Penyebaran kuesioner disebar pada 200 responden dengan metode random sampling. Dari penyebaran kuisoner tersebut terdapat 10 kuisoner yang tidak kembali, sehingga diperoleh total sampel sebanyak 190 responden.

Tabel 1. Profil Responden

\begin{tabular}{|c|c|c|}
\hline Kriteria & Klasifikasi & Jumlah \\
\hline \multirow{2}{*}{$\begin{array}{c}\text { Jenis } \\
\text { Kelamin }\end{array}$} & Pria & $57 \%$ \\
\hline & Wanita & $43 \%$ \\
\hline \multirow{6}{*}{ Pekerjaan } & Pelajar/ Mahasiswa & $82 \%$ \\
\hline & Pensiunan & - \\
\hline & PNS & $2 \%$ \\
\hline & Wiraswasta & $13 \%$ \\
\hline & Profesional & $3 \%$ \\
\hline & Lain Lain & $1 \%$ \\
\hline \multirow{6}{*}{ Agama } & Islam & $43 \%$ \\
\hline & Kristen Protestan & $24 \%$ \\
\hline & Katolik & $19 \%$ \\
\hline & Hindu & $1 \%$ \\
\hline & Kong $\mathrm{Hu} \mathrm{Chu}$ & $3 \%$ \\
\hline & Budha & $12 \%$ \\
\hline \multirow{4}{*}{ Usia } & $18-20$ tahun & $47 \%$ \\
\hline & $21-23$ tahun & $29 \%$ \\
\hline & $24-26$ tahun & $20 \%$ \\
\hline & $27-29$ tahun & $4 \%$ \\
\hline
\end{tabular}

Sumber: Data yang diolah
Dari data yang diperoleh,dilakukan uji validitas dan reliabilitas pada setiap variabel.

Tabel 2. Uji Validitas dan Reliabilitas

\begin{tabular}{|c|c|c|}
\hline $\begin{array}{c}\text { Item } \\
\text { Kuisoner }\end{array}$ & $\begin{array}{c}\text { Corrected } \\
\text { item-total } \\
\text { correlation }\end{array}$ & $\begin{array}{c}\text { Cronbach } \\
\text { Alpha }\end{array}$ \\
\hline I1 & 0,75 & 0,85 \\
\hline $\mathrm{I} 2$ & 0,716 & 0,859 \\
\hline $\mathrm{I} 3$ & 0,705 & 0,861 \\
\hline I4 & 0,743 & 0,852 \\
\hline I5 & 0,682 & 0,867 \\
\hline E1 & 0,484 & 0,753 \\
\hline E2 & 0,512 & 0,743 \\
\hline E3 & 0,59 & 0,721 \\
\hline $\mathrm{E} 4$ & 0,571 & 0,732 \\
\hline E5 & 0,648 & 0,692 \\
\hline A2 & 0,798 & 0,743 \\
\hline A3 & 0,753 & 0,786 \\
\hline A4 & 0,658 & 0,872 \\
\hline $\mathrm{P} 1$ & 0,845 & 0,882 \\
\hline $\mathrm{P} 2$ & 0,831 & 0,894 \\
\hline P3 & 0,831 & 0,883 \\
\hline Q1 & 0,734 & 0,743 \\
\hline Q2 & 0,735 & 0,746 \\
\hline Q3 & 0,641 & 0,837 \\
\hline $\mathrm{N} 2$ & 0,819 & 0,8 \\
\hline N3 & 0,848 & 0,774 \\
\hline $\mathrm{R} 1$ & 0,811 & 0,787 \\
\hline $\mathrm{R} 2$ & 0,792 & 0,805 \\
\hline R3 & 0,698 & 0,887 \\
\hline D1 & 0,833 & 0,835 \\
\hline D2 & 0,864 & 0,809 \\
\hline D3 & 0,741 & 0,916 \\
\hline
\end{tabular}

Sumber: Data yang diolah

Dalam penelitian ini, uji validitas akan menggunakan perbandingan nilai corrected item-total correlation hasil 


\section{JURNAL EKONOMI DAN MANAJEMEN \\ P-ISSN: 2598-9022/ E-ISSN: 2598-9618 \\ Available at: \\ http://e-journal.unipma.ac.id/index.php/capital}

pengolahan SPSS 17 dengan nilai $r$ tabel, dimana dengan jumlah sampel sebesar 190 responden, maka $\mathrm{r}$ tabel $=$ 0,1417. Uji reliabilitas akan menggunakan nilai cronbach's Alpha dimana item yang diukur dapat diterima bila nilai chonbach's alpha pada rentang 0,6 sampai 0,7 dan lebih dari 0,8 dikatakan baik (Sekaran dan Bougie, 2016). Hasil uji reliabilitas dan validitas menunjukan bahwa item pertanyaan pada kuisoner yang didistribusikan pada responden sudah valid dan reliabel. dengan pertanyaan penelitian, sehingga dapat dilakukan pengujian hipotesis.

Pengujian hipotesis menggunakan regresi dengan bantuan software SPSS 17.Hasil pengujian analisis regresi variabel intrinsic religiosity terhadap variabel memberi manfaat secara aktif menunjukan nilai $\beta=-0.041$, memberi manfaat secara pasif menunjukan nilai $\beta$ $=-0.087$, perilaku yang dapat dipertanyakan menunjukan nilai $\beta=$ 0.070, tidak merusak dan mempengaruhi secara positif menunjukan nilai $\beta=-0.204$, mendaur ulang menunjukan nilai $\beta=-0.170$ dan bertindak yang baik menunjukan nilai $\beta=-0.166$. Dari pengujian hipotesa yang pertama menunjukan bahwa hipotesa terdukung. Dengan kata lain, intrinsic religiosity memberi pengaruh negatif terhadap penilaian etika. Hasil ini berbeda dengan penelitian terdahulu (Arli et al (2017), dimana pada penelitian tersebut intrinsic religiosity berdampak negatif pada memberi manfaat secara aktif, memberi manfaat secara pasif, perilaku yang dapat dipertanyakan, tidak merusak dan mempengaruhi secara positif, tetapi berdampak positif terhadap mendaur ulang dan bertindak yang baik.

Pada pengujian hipotesis kedua variabel extrinsic religiosity terhadap variabel memberi manfaat secara aktif menunjukan nilai $\beta=0.161$, memberi manfaat secara pasif menunjukan nilai $\beta$ $=0,231$, perilaku yang dapat dipertanyakan menunjukan nilai $\beta=$ 0.201, tidak merusak dan mempengaruhi secara positif menunjukan nilai $\beta=0.532$, mendaur ulang $\beta=0.458$.dan bertindak yang baik menunjukan nilai $\beta=0.536$. Dari pengujian hipotesa yang kedua juga menunjukan bahwa hipotesa terdukung. Dengan kata lain, extrinsic religiosity memberi pengaruh positif terhadap penilaian etika. 


\section{JURNAL EKONOMI DAN MANAJEMEN \\ P-ISSN: 2598-9022/ E-ISSN: 2598-9618 \\ Available at: \\ http://e-journal.unipma.ac.id/index.php/capital}

\section{E. SIMPULAN}

Pada hipotesa pertama yaitu intrinsic religiosity memberi pengaruh negatif terhadap penilaian etika, memiliki arti bahwa semakin tinggi intrinsic religiositymaka mereka semakin tidak dapat menerima terhadap tindakan yang melanggar etika.Pada hipotesa kedua extrinsic religiosity memberi pengaruh positif terhadap penilaian etika,berarti bahwa semakin tinggi religiusitas ekstrinsik mereka makalebih besar kemungkinan responden akan menganggap memberi manfaat secara aktif, memberi manfaat secara pasif, perilaku yang dapat dipertanyakan, tidak merusak dan mempengaruhi secara positif, mendaur ulang dan bertindak yang baik sebagai hal yang dapat diterima.

Merujuk dari hasil penelitian ini maka nampak bahwa keyakinan agama pada generasi milenial masih memberi pengaruh terhadap penilaian etika. Oleh karena itu tidak mengherankan bila aksi boikot terhadap suatu produk yang mereka anggap tidak dapat diterima dalam penilaian etika. Hal ini perlu menjadi catatan penting bagi pada produsen yang menargetkan generasi milenial sebagai target pasar mereka.
Para produsen diharapkan dapat mempertimbangkan segala aspek yang memiliki potensi bertentangan dengan penilaian etika dalam berbisnis. Generasi milenial di perkotaan juga memiliki akes informasi yang lebih besar sehingga ketika terjadi dugaan pelanggaran etika, maka hal tersebut dapat dengan cepat disebarluaskan. Hal tersebut tentu akan merugikan bisnis.

Penelitian yang akan datang diharapkan dapat melengkapi keterbatasan dari penelitian ini, yaitu dengan membandingkan hasil penelitian ini dengan generasi milenial yang hidup jauh dari perkotaan sesuai dengan saran penelitian pada penelitian Arli (2017). Penelitian yang akan datang juga dapat melihat membandingkan besaran dampak antara intrinsic religiosity danextrinsic religiosity terhadap penilaian etika pada generasi milenial

\section{DAFTAR PUSTAKA}

Abdulrazak., Rula M. Al \& Gbadamosi., Ayantunji. (2017). Trust, religiosity, and relationship marketing: a conceptual overview of consumer brand loyalty. Society and Business Review, 12(3), 320-339.

Allport, G.W \& Ross, J.M. (1967). Personal religious orientation 


\section{JURNAL EKONOMI DAN MANAJEMEN \\ P-ISSN: 2598-9022/ E-ISSN: 2598-9618 \\ Available at: \\ http://e-journal.unipma.ac.id/index.php/capital}

and prejudice.Journal ofPersonality and Social Psychology, 5(4), 447-457.

Agag, Gomaa M., El-Masry \& Ahmed A. (2016). Cultural and religiosity drivers and satisfaction outcomes of consumer perceived deception in online shopping. Internet Research, 26 (4), 942-962.

Madni, A. R., Hamid, N. A., \& Rashid, S. M. (2016). An Association between Religiosity and Consumer Behavior: A Conceptual Piece. The Journal of Commerce, 8(3), 58.

Arli,,Denni. (2017). Does ethics need religion? Evaluating the importance of religiosity in consumer ethics. Marketing Intelligence \& Planning, 35(2), 205-221

Arli., Denni, Tjiptono., Fandy, Lasmono., Hari\&Anandya., Dudi. (2017). Do consumer ethics and consumer religiousness evolve across time? Insights from Millennials in Indonesia. Young Consumers. 18(4), 329-347

Leavy Patricia. (2017). Research Design : Quantitative, Qualitative, Mixed Methods, Arts-Based, and CommunityBased Participatory Research Approaches. New York :The Guilford Press

Purwandi., Lilik\& Ali Hasanuddin. (2018). Radicalism rising among educated
people?.Indonesia:

Alvara Research Center

Ramlet., Michael. (2018) What millennials expect from your brand. New York: Morning Consult

Sekaran,U. and Bougie, R.J. (2016). Research Methods for Business: A Skill Building Approach. United Kingdom: John Wiley and Sons Ltd.

Sihombing., O Sabrina. (2014). Identifiying current values of Indonesia Youth. Proceeding for The 9th International Conference on Business and Management Research "International Market Integration"

Swimberghe., Krist, Sharma., Dheeraj, Flurry\&Laura. (2011). Does a Consumer's Religion Really Matter in the Buyer-Seller Dyad? An Empirical Study Examining the Relationship Between Consumer Religious Commitment, Christian Conservatism and the Ethical Judgment of a Seller's Controversial Business Decision. Journal of Business Ethics, 102, 581-598

Vitell, S.J.\& Muncy, J. (2005). The Muncy-Vitell consumer ethics scale: a modification and application. Journal of Business Ethics, 62(3), 267-275

Vittel., J, Scoot. (2010). The Role of Religiosity in Business and Consumer Ethics: A Review of 


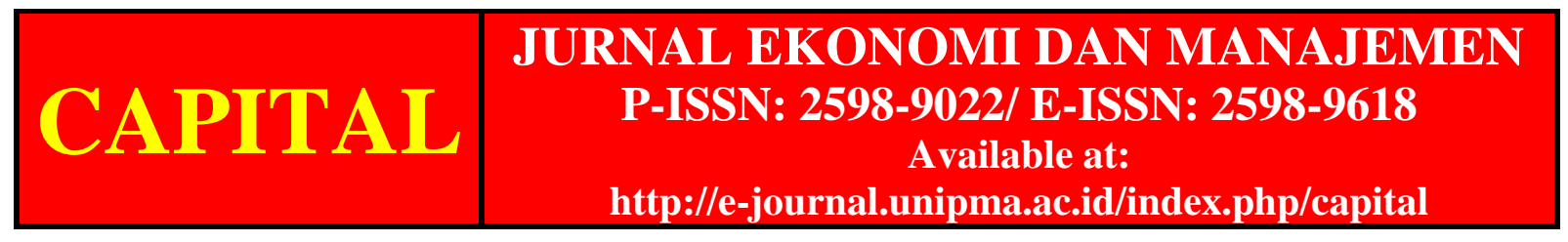

the Literature. Journal of

Business Ethics, 90:155-167

https://www.bkkbn.go.id/detailpost/bon

us- demografi-meningkatkan-

kualitas- penduduk-melalui-

keluarga. Diakses pada 03

Oktober 2018. 